\title{
Reflexões e dilemas sobre a ouvidoria pública no Brasil: uma análise das ouvidorias do Poder Executivo federal
}

Thales Torres Quintão

Universidade Federal de Minas Gerais (UFMG)

Este artigo busca fazer uma discussão analítica das ouvidorias públicas no Brasil especialmente as ouvidorias federais (ministérios) presentes no sistema e-Ouv - refletindo sobre os principais avanços e desafios encontrados por esse mecanismo ao estabelecer uma interface entre órgãos públicos e cidadãos. A pesquisa consistiu primeiramente numa revisão bibliográfica sobre as diferentes definições do conceito de ouvidoria pública na literatura (instrumento de gestão, canal de comunicação e instância participativa). Posteriormente, foi feita uma discussão crítica, desenvolvida com base em dados divulgados em estudos empíricos sobre os obstáculos para a atuação das ouvidorias, tomando como referência a sua autonomia política, autonomia técnica e prestação de contas. Posteriormente, de forma exploratória, foram examinados os atos normativos e a veiculação de informações sobre a ouvidoria nos sítios dos ministérios federais (todas elas integradas ao e-Ouv), como forma de compreender o envolvimento desse mecanismo no policy cycle. A conclusão alcançada foi a de que o dilema que cerca a ouvidoria pública é o precário desenvolvimento de prestação de contas para com a sociedade como um todo, o que inviabiliza o fomento da própria accountability.

Palavras-chave: ouvidoria pública, accountability, análise administrativa, Poder Executivo Federal, Brasil

[Artigo recebido em 23 de julho de 2018. Aprovado em 20 de fevereiro de 2019.] 
Reflexiones y dilemas sobre el Defensor del Pueblo (ouvidoria pública) en Brasil: un análisis del Defensor del Ejecutivo Federal

Este trabajo busca hacer una discusión analítica de las defensorías del pueblo (ouvidorias) en Brasil-especialmente las ouvidorias federales presentes en el sistema e-Ouvreflexionando sobre los principales avances y desafíos encontrados por ese mecanismo al establecer una interfaz entre organismos públicos y ciudadanos. La investigación consistió primero en una revisión bibliográfica sobre las diferentes definiciones del concepto de defensoría del pueblo en la literatura (instrumento de gestión, canal de comunicación e instancia participativa), y en el establecimiento de una discusión crítica, desarrollada con base en datos divulgados en estudios empíricos sobre los obstáculos para la actuación de las ouvidorias, tomando como referencia su autonomía política, autonomía técnica y rendición de cuentas. Posteriormente, de manera exploratoria, se han hecho un examen de los actos normativos y la transmisión de información sobre la ouvidoria en los sitios de los ministerios federales (todas ellas integradas al e-Ouv), como forma de comprender la implicación de ese mecanismo en el ciclo de las políticas públicas. La conclusión alcanzada fue que el dilema de las ouvidorias es el precario desarrollo de rendición de cuentas para con la sociedad, lo que inviabiliza el fomento de la propia accountability.

Palabras clave: ombudsman público, accountability, análisis administrativo, Poder Ejecutivo Federal, Brasil

\section{Reflections and dilemmas about the public ombudsman in Brazil: an analysis of the ombudsman's offices of the Federal Executive Branch}

This paper aims to make an analytical discussion of the public ombudsmen in Brazil especially the federal ombudsmen in the e-Ouv system - reflecting on the main advances and challenges faced by this mechanism in order to establish an interface between public agencies and citizens. Primarily, the research consisted of a bibliographical review of the definitions of the concept of public ombudsman in the literature (management tool, communication channel and participatory instance), and a critical discussion developed based on data published in empirical studies about the obstacles to the work of ombudsmen, using the following concepts: political autonomy, technical autonomy, and accountability. Subsequently, in an exploratory way, we examine the normative acts and the disclosure of information about the ombudsman's office in the Federal Ministry websites (all integrated with the e-Ouv system). The aim is to understand the involvement of this mechanism in the policy cycle. The conclusion is that the main dilemma about public ombudsman is the precarious development of accountability.

Keywords: public ombudsman, accountability, administrative analysis, Poder Executivo Federal, Brazil 


\section{Introdução}

A Lei de Acesso à Informação (LAI) promulgada em 2011 (n¹2.527) e o decreto que institui a Política de Participação Social e o Sistema Nacional de Participação Social de 2014 (n8.243), colocaram a ouvidoria pública em maior evidência dentro do campo político brasileiro. Afinal, a partir desse momento, maiores responsabilidades foram instituídas e, consequentemente, ampliou-se a expectativa (e as demandas) para que a ouvidoria se configure cada vez mais como uma arena de controle e participação social, abrigando em alguns casos, inclusive, os serviços de informações ao cidadão (SIC), com vistas a garantir o direito ao acesso à informação.

A primeira ouvidoria pública instalada no país foi no município de Curitiba, via decreto, em 1986. A partir da Constituição Federal de 1988, em que se estabelecem os princípios de impessoalidade e publicidade referentes aos atos provenientes da administração pública, as ouvidorias públicas se espalharam pelo país, nos três poderes republicanos e nos três níveis de governo, como forma de assegurar tais princípios (LYRA, 2004). Além disso, a própria implantação de ouvidorias tem sido estimulada pelo Governo Federal.Esse processo vai desde a implantação da OuvidoriaGeral da União (OGU), criada em 2002, órgão este que estabelece as diretrizes e orientações, e produz cartilhas que fundamentam o padrão de ouvidorias do Poder Executivo federal, além de coordená-las tecnicamente até a aprovação daemenda constitucional no 45, de 8 de dezembro de 2004, que promulga a criação de ouvidorias no Poder Judiciário e no Ministério Público, no âmbito federal e dos estados, sendo tal ação efetivada somente sete anos após a publicação da aludida emenda.

Ressalta-se que a Ouvidoria Geral da União (OGU) faz parte da Controladoria Geral da União (CGU), a qual passou a ser vinculada ao Ministério da Transparência, Fiscalização e Controle com o governo Temer em maio de $2016^{1}$, contexto que compreende a análise dos dados aqui empreendida, algo que será abordado mais adiante.

Deve-se citar também o decreto de 17 de setembro de 2013, referente à constituição de um sistema nacional de ouvidorias situadas no Poder Executivo federal. Tal decreto obriga a todos os órgãos de sua estrutura a implantar uma ouvidoria, constituindo, assim, o sistema e-Ouv² - sistema informatizado criado em

\footnotetext{
${ }^{1}$ Anteriormente a Controladoria Geral da União (CGU) era um órgão vinculado diretamente à Presidência.

${ }^{2}$ Em consulta no dia 06/02/2017, 112 ouvidorias aderiram ao sistema e-Ouv, classificadas em sete segmentos diferentes: administração direta; estatais; hospitais; instituições de ensino; organizações militares; outras autarquias e fundações; e sistema financeiro. O segmento que aparece com maior incidência é o das as instituições de ensino (62 casos), e o de menor incidência é o das organizações militares e o sistema financeiro, com apenas um caso cada. http://www.ouvidorias.gov.br/cidadao/lista-de-ouvidorias/adesoes-ao-e-ouv.
} 
dezembro de 2014, que dinamiza e integra o fluxo comunicacional entre as diversas ouvidorias que o engloba, desenvolvido pela Controladoria Geral da União (CGU) ${ }^{3}$. Ademais, há o Programa de Fortalecimento das Ouvidorias (Profort) instituído via portaria (n050.253), em dezembro de 2015, visando apoiar a criação e o desenvolvimento de ouvidorias públicas, assim como o aperfeiçoamento da gestão de processos e a atuação integrada das ouvidorias ${ }^{4}$.

De acordo com a OGU em 2002, havia 40 ouvidorias no Poder Executivo federal; já em 2014 esse número passou para 285, ou seja, um crescimento de 612,5\% em doze anos. Porém, Oliveira (2010) pontua o problema de associar a disseminação de ouvidorias públicas no Brasilcom sua competência em si, algo que ele denomina de "difusão deturpada". Como exemplo desse fenômeno, ele cita a alocação da ouvidoria em um mesmo órgão que exerce a função de corregedoria, e questiona: qual seria a importância de se instalar uma ouvidoria em uma Secretaria de Assuntos Institucionais? (OLIVEIRA, 2010, p.173).

Todavia, reconhece-se o processo de fortalecimento das ouvidorias também no âmbito estadual. Esse fato se fundamenta pela criação de redes de ouvidorias, que integram diversas secretarias e órgãos estaduais, com vistas a aperfeiçoar o compartilhamento de informações e a maior integração entre elas. Um exemplo é a Rede Mineira de Ouvidorias Públicas (Rede Ouvir-MG), formalizada em setembro de 2013, que inclui as seguintes ouvidorias: a do Tribunal de Contas do eEstado (TCE-MG); a do Ministério Público de Minas Gerais (MPMG); a do Tribunal de Justiça (TJ-MG); a da Assembleia Legislativa de Minas Gerais (ALMG); a do Tribunal Regional Eleitoral (TRE); e a da Ouvidoria Geral (OGE) ${ }^{5}$. A principal função dessa rede é dar mais dinamicidade ao fluxo de recebimento, tratamento e respostas às demandas.

Além dessa integração no âmbito estadual, há um processo de desenvolvimento de redes de ouvidorias municipais. O melhor exemplo disso é a rede de ouvidorias municipais do Estado de Pernambuco, que utiliza o modelo e sistemaadotado pela Ouvidoria Geral do Estado, que é a responsável por coordenar a rede de ouvidorias do governo pernambucano ${ }^{6}$. Por fim, cabe ressaltar o trabalho desenvolvido pelo Conselho Nacional da Justiça (CNJ) para a consolidação das ouvidorias dentro do Poder Judiciário. A ouvidoria do CNJ foi criada em 2009, e desde então tem assumido

\footnotetext{
${ }^{3}$ Instrução normativa $N^{\circ} 1$ da OGU

${ }^{4}$ O Profort oferece cursos/treinamentos sobre a atividade da ouvidoria; elaboração/ distribuição do material técnico/orientativo; e cessão gratuita do código fonte do sistema e-Ouv.

${ }^{5} \mathrm{E}$ isso envolve também as ditas "ouvidorias especializadas" que são: ambiental; educacional; fazenda, patrimônio e licitações públicas; sistema penitenciário; polícia; e saúde.

${ }^{6}$ Atualmente, a Ouvidoria Geral coordena 48 ouvidorias centrais: acesso: 05/02/2019 - http://www.portaisgoverno. pe.gov.br/web/ouvidoria.
} 
um papel de mapear e realizar relatórios acerca do funcionamento das ouvidorias nos tribunais, e de organizar congressos e seminários para discutir a atuação dessas ouvidorias com vistas a reforçar o seu papel de mediação e conciliação de conflitos.

Embora muito se tenha avançado no processo de implementação das ouvidorias ${ }^{7}$, alguns estudos têm mostrado algumas deficiências da sua atuação como instância de controle e participação social, e, assim, para o aprimoramento da gestão pública. Essas deficiências se centram basicamente na conformação do seu desenho institucional - que pode resultar em sua autonomia política e técnica - e na sua capacidade de prestação de $\operatorname{contas}^{8}$, principalmente para com o seu público externo (LIMA NETO; DURÁN, 2016). Além disso, há conflitos conceituais (e por que não políticos?) sobre a ouvidoria pública: (1) qual seu papel preponderante (instância de participação ou de gestão; controle interno ou externo), (2) qual o perfil do ouvidor (profissionalização ou militante), e (3) como se dá a conformação da sua legitimidade (processo de escolha do ouvidor; atribuição ou não de mandato; localização interna ou externa). Todo esse processo gera modelos em disputa nas discussões teóricas acerca das ouvidorias públicas (LYRA, 2014), e inclusive na própria conformação do seu sistema nacional (LYRA; LEMOS, 2014; ROMÃo, 2016).

Portanto, o objetivo principal deste artigo é fazer uma discussão analítica sobre os desenhos assumidos das ouvidorias públicas no Brasil, bem como as políticas de comunicação por elas desenvolvidas. Essa análise se dará tanto com base em dados secundários, quanto na análise empírica aqui realizada sobre as ouvidorias dos ministérios federais.

Desse modo, o artigo está divido em mais três seções, para além desta introdução e das considerações finais. Primeiramente, será feita uma revisão bibliográfica, buscando demonstrar as diversas frentes analíticas e formas de interpretação acerca da ouvidoria pública. Consideramos existir três campos teóricos sobre ela: ouvidoria como instrumento de gestão; como canal de comunicação organizacional; e instância participativa.

Em seguida, com base em dados secundários, coletados por meio de surveys e mapeamento dessas instâncias (BORGES, 2012; MENEZES, 2017, 2016), serão expostas algumas deficiências do seu desenho institucional, apontando empecilhos para a sua institucionalização perante a esfera pública. Parte-se da premissa de que a forma como a ouvidoria é desenhada contribui para a sua distribuição de poder e

\footnotetext{
7 Notícia publicada no dia 11/04/2017. no portal da Controladoria Geral da União, mostra que registros do Sistema de ouvidorias do Poder Executivo (e-Ouv) aumentaram em 95\% quando comparados com os três primeiros meses de 2016. Esse crescimento deve-se à integração do e-Ouv com as plataformas operacionais do Reclame Aqui, e com o Portal de serviços do Governo Federal do Ministério do Planejamento.

8 Esses conceitos serão desenvolvidos mais adiante, na terceira seção deste artigo.
} 
para o seu funcionamento, ou seja, a sua capacidade para desempenhar o controle interno e social e fomentar políticas públicas mais participativas (FUNG, 2003, 2006).

Por último, será feita a análise empírica acerca dos atos normativos das ouvidorias dos ministérios públicos federais e da política de comunicação feita por elas, analisando os seus respectivos sites (posicionamento, acessibilidade, e informações disponíveis) (PINHO, 2008; RAUPP; PINHO, 2013), como uma proxy de mensurar como elas estão incluídas nesses espaços institucionais e de sua importância, o que nos aproxima para a dimensão da prestação de contas para o público externo.

\section{Ouvidoria pública: conceitos e conflitos}

A ouvidoria pública foi indiretamente fundamentada juridicamente com a Constituição de 1988, em seu artigo 37ํㅡ, parágrafo 3, que em sua redação original diz: "as reclamações relativas à prestação de serviço público serão disciplinadas em lei". Essa instância (a ouvidoria) possui o potencial de mediar as relações entre o Estado e a sociedade e propiciar um mecanismo de participação de incidência direta (CORTES, 2011), ao transportar o discurso informal do cidadão para dentro da administração pública, e assim transformá-lo em formal e institucionalizado (NASSIF, 2009).

Esse instituto se organiza de acordo com o princípio igualitário, ao reconhecer os cidadãos, sem distinção entre eles, como sujeitos possuidores de um conjunto e sistema de direitos, e por serem capazes de demandar e reivindicar junto ao Estado. Lyra (2004, p. 121) nos diz que, por meio da ouvidoria, o cidadão é transportado para dentro da administração pública. Ele passa a ter voz ativa, na medida em que suas críticas, denúncias, sugestões e solicitações são recebidas diretamente pela administração pública, o que é positivo para a retroalimentação do processo, ou seja, para corrigir e aprimorar os atos governamentais e as políticas. A ouvidoria pública possibilita democratizar o ingresso do cidadão à administração pública. Por meio dela se assegura o direito do cidadão de requerer informações e dados de seu interesse ou coletivo, principalmente com a Lei de Acesso à Informação (LAI), além de desempenhar a função de ser um espaço de mediação entre o estado e a sociedade, com a busca pela solução de conflitos via extrajudicial, com base na magistratura de persuasão do ouvidor (ROMERO; SANT'ANNA, 2014; VALDÉS, 2011).

Tem-se a ideia que a ouvidoria se pauta na defesa do cidadão e dos seus respectivos direitos. Segundo Comparato $(2016,2012)$ as ouvidorias encorajam o exercício de um direito civil fundamental: o direito de petição e interpelação do poder público; e de envolver os cidadãos no processo de avaliação da execução dos serviços públicos. Além disso, as ouvidorias públicas, ainda que não tenham a 
atribuição de exercer diretamente a accountability, por não terem capacidade de sanção nem punição, podem pressionar os mecanismos de controle tradicionais a agir, por meio de recomendações a esses órgãos, o que geraria a justificação pública decisória (LAVALLE; VeRA, 2012), e o exercício do poder de forma transparente (accountability como answerability) (SCHEDLER, 1999). Nesse sentido, esse mecanismo teria a capacidade de informar o aparato estatal acerca das demandas e sugestões, numa relação de contribuição e interação com os conselhos de políticas públicas e aperfeiçoar o controle social sobre tais políticas (COMPARATO, 2016), ou mesmo ativar um mecanismo de accountability horizontal como o Ministério Público (Isunza, HeVIA, 2006; LAVALLe, VerA, 2010).

Outro ponto salientado pelos estudiosos é o caráter crítico propositivo que essa instância pode desempenhar. O ouvidor possuiria um "olhar de fora", não "sugado" e "corrompido" pela máquina pública, o que possibilitaria estabelecer uma reflexão crítica da organização pública, a partir de uma análise macroestrutural do seu funcionamento e eficiência, por meio do uso da razão pública (MENEZES: LIMA Neto; CARDoso, 2016). Dessa forma, seria possível criar inovações ou mudanças estruturais, que aperfeiçoem os serviços públicos e a defesa dos direitos dos cidadãos (CARdoso; LIMA Neto; AlCÂnTARA, 2013).

Todavia, como pontuado na introdução deste artigo, há inúmeros conflitos conceituais (e políticos) em torno do papel preponderante e as suas características operacionais da ouvidoria. Pode-se distinguir a compreensão dessa instância em três campos teóricos: 1) ouvidoria como instrumento de gestão; 2) como canal de comunicação organizacional; 3) e como instância participativa. Considerando-os como tipos ideais weberianos, esses campos partem de diferentes paradigmas e racionalidades, e, consequentemente, focam em determinados objetivos e designs para a ouvidoria pública. Ressalta-se que a ouvidoria como instrumento de gestão e como instância participativaestão em espectros teóricos mais distantes entre eles, com menor tendência de aproximações, enquanto a de canal comunicacional ocupa a posição central nesses campos (Figura 1).

\section{Figura 1 - Campos teóricos da ouvidoria pública}

Instrumento de gestão

Canal de comunicação organizacional

Instância participativa

Fonte: elaboração própria

A ideia da ouvidoria como instrumento de gestão a compreende como um termômetro para a melhoria dos serviços públicos ofertados, ou o aperfeiçoamento do órgão e a sua modernização administrativa (LYRA, 2008). A sua atuação seria de dentro para dentro, para auxiliá-la no controle interno e na avaliação dos 
procedimentos e dos resultados da gestão pública (ANTERO, 2014; BAESSO, 2013; ANTUNES, 2010). A racionalidade preponderante é a instrumental e material, baseada em adequação de meios e fins e cálculos de demanda, visando à satisfação utilitária e pontual dos cidadãos-usuários de tais serviços (MARIO, 2011), ou seja, o objetivo final é a eficiência, e os princípios são oriundos da lógica do mercado (GOMES, 2016). Nessas ouvidorias prepondera a adoção de técnicas gerenciais de gestão, com a profissionalização do próprio ouvidor, o que aproxima as características da ouvidoria pública com a privada ${ }^{9}$, em que a ouvidoria é o espaço destinado quando o problema não fora resolvido inicialmente pelos serviços de atendimento ao cidadão (SACS). Assim, ela opera quando há a reincidência do erro, ou quando não houve resolução da queixa por outras vias, sendo esses problemas mais sensíveis e complexos, com foco mais para a qualidade do serviço e produto, mas reproduzindo os modos de produção existentes. Esse tipo de ouvidoria está centrado dentro da perspectiva do New Public Management, que assegura a participação do cidadão de forma passiva, menos conflituosa e contestatória (DAGNINO, 2004). Nesse contexto, o cidadão é transvestido para a noção de cliente dos serviços públicos.

Quanto ao desenho desse tipo de ouvidoria, ele se localiza no próprio órgão em que elas estão, ou seja, é interno. Geralmente, tal instância é considerada com autonomia política e técnica restrita, pois o ouvidor é escolhido por critérios subjetivos e por livre nomeação do dirigente máximo a que ela está submetida. Ele não possui atribuição de mandato, podendo ser exonerado a qualquer momento, além de possuir dependência financeira e administrativa ao poder ou entidade onde está localizada (GOMES, 2016; LYRA, 2014).

Já o campo que entende a ouvidoria como um canal de comunicação, parte de estudos que consideram a ouvidoria como uma mídia organizacional. Neste, a ouvidoria tem a função de ser um espaço que estabelece uma relação bilateral, com trocas comunicativas e dialógicas entre o cidadão e a organização pública (IASBECK, 2010). A interface socio estatal configuraria em uma colaboração informativa entre esses dois polos, informando-se e comunicando-se mutuamente (ISUNZA, HEVIA, 2006).

Para esses estudos, a ouvidoria adota uma dupla representação e, assim, faz uma mediação entre a organização e o cidadão, uma vez que fala com o cidadão em nome do órgão público, e fala pelo cidadão no âmbito interno desse órgão (IASBECK, 2012). Desse modo, a ouvidoria teria que se manter distante e próxima simultaneamente, tanto do cidadão quanto do contexto em que ela está inserida, como forma de

\footnotetext{
${ }^{9}$ Entretanto, uma parte da literatura critica essa aproximação entre os preceitos que regem a ouvidoria pública para com a ouvidoria, dizendo que as duas partem de paradigmas diferentes, e assim possuem objetivos distintos. Para saber mais ver: Lyra (2011c).
} 
manter a sua impessoalidade e conseguir intermediar os conflitos. Nesse sentido, tem-se que a ouvidoria precisa estabelecer os vínculos existentes entre esses dois polos, ao procurar manter os fluxos informacionais e comunicacionais contínuos.

Quem procura a ouvidoria demonstra que quer tratar e manter o vínculo com a instituição, mesmo quando faz uma reclamação. O desejo é de estreitar o vínculo, e não o romper. A ouvidoria atua como um canal de comunicação quando, além de mediar conflitos, fortalece e revigora os relacionamentos (BASTOS; MARCHIORI; MORAES, 2012), mantendo o vínculo entre a organização pública e o cidadão. Esse vínculo é fundamental para o fomento da cultura da transparência e estabelecimento discursivo (QUINTÃo; CASTRO, 2014). Todavia, reconhece-se que a ideia da comunicação aqui referida se situa de forma interna à organização em questão, ou seja, não se tem uma noção mais ampla e sistêmica em que o diálogo esteja integrado para outras arenas, como outras ouvidorias públicas, ou até mesmo para mecanismos de controle ou participação, como Ministério Público ou conferências de políticas. Em suma, não se refere a um sistema deliberativo.

Destaca-se que esse campo dá muita atenção à linguagem utilizada pela ouvidoria, decorrente da necessidade de adequá-la (códigos verbais e não verbais) para o público a quem ela se destina (cidadão ou organização) e o seu lugar de fala (quem ela representa). Refere-se às trocas discursivas que envolvem essa relação, visando evitar o preconceito linguístico e o uso demasiado de termos técnicos por parte da ouvidoria, e a defesa da gestão tecnológica informacional - para auxiliar na fluidez e nas trocas discursivas entre cidadão e organização pública, procurando aferir e consolidar a imagem da instituição junto aos cidadãos (COELHO, 2012; Romero, SANT'ANNA, 2014; SiLva et al., 2012).

Quanto ao desenho da ouvidoria, tal perspectiva não se atém muito a essa questão; há menções esporádicas de que esse canal deveria estar alinhado aos cargos executivos de poder decisório, para o exercício da crítica autônoma e livre (IASBECK, 2010, 2012). Todavia, não há, por exemplo, um desenvolvimento analítico acerca do processo de escolha do ouvidor, e nem se ele deve ter atribuição de mandato, ou mesmo independência orçamentária e administrativa.

Por fim, a ouvidoria como instância participativa volta suas atenções para a capacidade da ouvidoria em defender prioritariamente os direitos dos cidadãos, a busca pela justiça social, e a construção da cidadania (LYRA, 2008, 2011a). Porém, não se deve deixar de lado a eficiência na prestação dos serviços públicos, a ampliação da inclusão social e política, e a sua efetividade, compreendida como "a capacidade de intervir e mudar a realidade social" (CARDoso, 2011, p.212). Nesse tipo de paradigma, a ouvidoria é vista como um arranjo participativo institucional, que amplia os espaços de envolvimento político, e possibilita uma incidência direta das 
demandas e reivindicações dos cidadãos no publicus. Esse arranjo estaria integrado ao ciclo regular das políticas públicas, que ao remeter autores participacionistas, teria como finalidades romper com as estruturas mais hierarquizadas de autoridades de poder, a busca pela renovação das práticas políticas e sociais, e a formação de uma nova gramática de atores possuidores de direitos (PATEMAN, 1992, 2012; SANTOS, AVRITZER, 2002). Nesse sentido, a ouvidoria pública teria uma finalidade pedagógica e de aprendizado político, primeiramente por explicitar o próprio funcionamento do aparato estatal e sua burocracia, e depois no reconhecimento da materialidade dos direitos e deveres dos cidadãos.

Segundo essa perspectiva, a ouvidoria, predominantemente, deveria contar com a participação da sociedade civil, ou seja, ela é vista como um instrumento de controle social ou de participação popular. O ouvidor seria escolhido via eleição indireta por um colegiado independente, formado por entidades civis e movimentos sociais, da instituição onde atuará ${ }^{10}$, acrescido da defesa da existência de um conselho consultivo composto pela sociedade civil que permite a proposição de diretrizes para o seu funcionamento, e de monitorar os seus trabalhos e acompanhar a atuação do ouvidor(LYRA, 2011b). A garantia da posição de ouvidor seria assegurada por meio do mandato (SILVA et al., 2012), e que este não coincidiria com o tempo político que o governante estará no poder (ZAVERUCHA, 2008) ${ }^{11}$.

A racionalidade preponderante é a dialógica, ou seja, as ouvidorias são guiadas por valores da sociedade, com vistas à equidade social, com caráter dialógico e comunicacional (GOMES, 2006), diferentemente da perspectiva de ouvidoria como instrumento de gestão, cuja racionalidade mais forte é a instrumental. Além disso, é na perspectiva participacionista que o requisito para o cargo de ouvidor se dá com base na sua militância na defesa de direitos da cidadania, enquantona de gestão há um viés mais tecnocrático, defendendo a sua profissionalização (GoMES, 2016; LYRA, 2008). Todos esses pressupostos da instância participativase direcionam a um modelo denominado de ouvidorias autônomas e democráticas (LYRA, 2014).

\footnotetext{
10 Segundo Lyra (2011b), essa situação materializa o "controle extra orgânico", uma vez que a ouvidoria está fora do órgão a ser monitorado, e envolve um colegiado independente na hora de escolher o ouvidor. Esse colegiado formado pela sociedade civil e movimentos sociais elabora uma lista tríplice e a envia para o poder público, que assim, define a pessoa a ser o ouvidor. Esse modelo iniciou-se em 1995, no Estado de São Paulo, na ouvidoria de política. No entanto, o aparato estatal é quem teria a palavra final na hora de definir sobre quem seria o ouvidor, o que pode dar margem de manobra, escolhendo pessoas com menos votos nessa lista, ou com menor militância na pauta em questão. Por isso, na IX Conferência Nacional de Direitos Humanos de 2004, determinou-se um modelo em que na hipótese de o mais votado dessa lista alcançar cinquenta por cento dos votos das organizações civis, este será automaticamente homologado como ouvidor do órgão em questão.

${ }^{11}$ Como pontuado por Zaverucha (2008): "o calendário político ficaria desatrelado do calendário administrativo. Com o objetivo de ficar institucionalmente claro que a ouvidoria é muito mais um órgão de Estado do que de governo" (ZAVERUCHA, 2008, P.226).
} 
Por fim, uma diferença crucial entre a ouvidoria como instrumento da democracia participativa e o de canal de comunicação é que a primeira defende essencialmente que a ouvidoria deveria atuar de forma semelhante aos institutos dos Defensores del Pueblo, presentes na Ibero-América, cuja função principal é a garantia e a tutela dos direitos humanos, sendo uma instância política independente (LYRA; CONSTELA, 2012), enquanto a ouvidoria como mídia organizacional se volta para o seu papel de mediação entre as partes, não assumindo previamente a defesa das demandas dos cidadãos (IASBECK, 2012).

O Quadro 01 abaixo resume as principais características e entendimentos diversos acerca da ouvidoria nesses três campos teóricos elucidados.

\section{Quadro 01 - Campos teóricos da ouvidoria pública}

\begin{tabular}{|c|c|c|c|c|c|}
\hline $\begin{array}{l}\text { Campo } \\
\text { Teórico }\end{array}$ & Racionalidade & Controle & Objetivos & $\begin{array}{l}\text { Ouvidor e } \\
\text { processo de } \\
\text { escolha }\end{array}$ & Paradigma \\
\hline $\begin{array}{l}\text { Instrumento } \\
\text { de gestão }\end{array}$ & Instrumental & Interno & $\begin{array}{l}\text { Eficiência dos } \\
\text { serviços públicos } \\
\text { e modernização } \\
\text { administrativa }\end{array}$ & $\begin{array}{l}\text { Profissionalização } \\
\text { / escolhido por } \\
\text { livre nomeação }\end{array}$ & $\begin{array}{l}\text { New Public } \\
\text { Management }\end{array}$ \\
\hline $\begin{array}{l}\text { Canal de } \\
\text { comunicação }\end{array}$ & $\begin{array}{l}\text { Comunicativa } \\
\text { não sistêmica }\end{array}$ & Interno & $\begin{array}{l}\text { Mediação de } \\
\text { conflitos e dupla } \\
\text { representação }\end{array}$ & $\begin{array}{l}\text { Aliado aos } \\
\text { cargos de poder } \\
\text { decisório }\end{array}$ & $\begin{array}{l}\text { Relações } \\
\text { Públicas }\end{array}$ \\
\hline $\begin{array}{l}\text { Instrumento } \\
\text { participativo }\end{array}$ & $\begin{array}{l}\text { Dialógica } \\
\text { sistêmica }\end{array}$ & $\begin{array}{l}\text { Externo } \\
\text { e social }\end{array}$ & $\begin{array}{l}\text { Defesa dos } \\
\text { direitos dos } \\
\text { cidadãos }\end{array}$ & $\begin{array}{l}\text { Militante / } \\
\text { colegiado } \\
\text { independente e } \\
\text { participação da } \\
\text { sociedade civil }\end{array}$ & Participacionista \\
\hline
\end{tabular}

Fonte: elaboração própria

\section{Ouvidoria pública e evidências empíricas: autonomia política, técnica e prestação de contas}

Como já explicitado na introdução deste artigo, em geral, três dimensões são utilizadas para analisar a atuação da ouvidoria pública: autonomia política; autonomia técnica e prestação de contas (LIMA NETO; DURÁN, 2016). Os estudos para mensurar tais dimensões consistem, principalmente, no exame dos instrumentos normativos da ouvidoria (CARDoso, 2012, 2010; GOMES, 2016; LYRA, 2014, 2011a;VALDÉS, 2011), o que pode ser uma estratégia limitada por não conseguir 
entender de forma profunda as relações de poder, os contextos, e os atores que estão imbricados diretamente e indiretamente no funcionamento da ouvidoria ${ }^{12}$.

A autonomia política diz respeito à independência e à liberdade de atuação das ouvidorias e seu insulamento com relação às ingerências e interesses de partidos e grupos políticos. Por exemplo: o processo de escolha do ouvidor; atribuição de mandato; e delimitação normativa das funções da ouvidoria (LYRA, 2011b; CARDOSO, 2010). Todos esses fatores podem concernir por conferir maior legitimidade por parte da ouvidoria perante a sociedade.

Já a autonomia técnica é a capacidade da ouvidoria influenciar no processo decisório, com seus relatórios analíticos e sugestões elaboradas com base na magistratura de persuasão. Por exemplo: a colaboração dos servidores e empregados frente às demandas apresentadas à ouvidoria (caráter prioritário e de urgência de resposta); o sigilo à identidade do manifestante como forma de evitar represálias; a fixação de prazo para resposta do manifestante; a atribuição e relação da ouvidoria perante a Lei de Acesso à Informação (LAI), independência orçamentária e administrativa; e o acesso do ouvidor às altas instâncias de tomada de decisão (LIMA Neto; DurÁN, 2016; MEnEZES, 2016; QuinTÃo, 2015).

Por fim, a prestação de contas trata da publicização tanto das manifestações recebidas pela ouvidoria, quanto do seu percurso institucional, que se referem às ações tomadas para tal, o que concerne ao princípio da justificação pública e do controle social. Por exemplo: ampla divulgação dos relatórios feitos pela ouvidoria; divulgação das ações da ouvidoria em formato notícia; organização em rede (sistema de ouvidorias) (QUINTÃo, CASTRO, 2014; SILVA et al., 2012; LYRA, 2011b).

Algumas evidências empíricas são cruciais para entendermos mais essas três dimensões analíticas correlacionadas à atuação da ouvidoria pública no Brasil. Muitos dos dados aqui utilizados são advindos do Projeto Coleta OGU de 201413, realizado em parceria com o Instituto de Pesquisa Econômica Aplicada (Ipea), com dados de 2013 e 2014 (Menezes, 2017, 2016, 2015), e da Pesquisa Diagnóstico

\footnotetext{
${ }^{12}$ Nesse sentido, advogamos a necessidade de fazer uma espécie de triangulação de dados, tendo como fundamental importância o uso de entrevistas semiestruturadas ou em profundidade, com ouvidores, servidores públicos ou com a própria população que acionou a ouvidoria, ou sobre os frames presentes acerca das ouvidorias nos portais institucionais, como incipientes estudos têm feito atualmente (MENEZES, 2017; QUINTÃo, 2015; SILVA et al, 2012; MARIO, 2011).

${ }^{13}$ Tal projeto teve como amostra 174 ouvidorias de órgãos e entidades da administração pública direta e indireta, nos níveis federais, estaduais e distritais, abrangidas todas as regiões do país. Do total, 163 pertencem ao âmbito federal, 10 ao estadual, e uma ao nível distrital.
} 
das Ouvidorias do Poder Executivo, com dados de 2011, realizado em parceria com a Unesco (BORGES, 2012) ${ }^{14}$.

Quanto à primeira dimensão (autonomia política), na maior parte das ouvidorias públicas federais (74\%) a escolha do ouvidor se dá por meio da livre nomeação do gestor máximo do respectivo órgão ou entidade (MENEZES, 2015). Por ter como característica a unipessoalidade, o ouvidor centraliza em torno de sua pessoa a gestão desse meio e suas respectivas funções atributivas (SILVA et al., 2012, p. 46.) O caráter para a autonomia do ouvidor é essencialmente político e diz respeito à relação de poder que está inserida no jogo entre o titular da ouvidoria e o órgão ou instituição sobre a qual ele exerce o monitoramento. A ideia é que as ouvidorias não podem ser organizadas nem controladas pelas instituições às quais elas dirigem as suas atenções, sob pena de comprometerem o propósito público.

Em segundo lugar, apenas 37\% dos ouvidores possuem mandato (MENEZES, 2015), o que permitiria que o ouvidor pudesse exercer suas funções e atividades com um mínimo de independência. Ele possuiria maior segurança no desenrolar dos trabalhos, garantindo a sua não destituição a qualquer momento de acordo com o livre arbítrio do gestor máximo, mas sim com base em uma espécie de recall de mandato composto por decisão do conselho consultivo (MENEZES; LIMA Neto; CARdoso, 2016). A instituição do mandato se faz mais presente nas agências reguladoras e universidades ${ }^{15}$.

Contudo, reconhece-se a importância da renovação do ouvidor, possibilitando a sua recondução em apenas um período, para que a ouvidoria seja um espaço de fomento para novos pensamentos e projetos, tendo menor vinculação ao status quo. Por fim, o terceiro ponto diz respeito à subordinação hierárquica das ouvidorias federais, nas quais em $77 \%$ delas a subordinação é em relação ao gestor máximo, e apenas $18 \%$ se subordinam hierarquicamente a outras unidades nas respectivas organizações (MENEZES, 2015), o que novamente pode diminuir seu status funcional,

\footnotetext{
${ }^{14}$ Esse estudo consistiu em dois tipos de questionários. O primeiro questionário consistia em um levantamento das ouvidorias e o segundo procurava avaliar a percepção dos ouvidores acerca dos temas correlatos à instituição ouvidoria. Das 165 ouvidorias inseridas na Relação das ouvidorias da CGU, 116 responderam ao primeiro questionário, e 99 responderam ao segundo. Para a realização do estudo, utilizou-se de visitas técnicas para a realização de entrevistas individuais junto aos ouvidores, bem como a sua equipe; e do envio de questionário via webmail.

${ }^{15}$ O próprio Ouvidor-Geral da União não possui mandato. Desde a sua criação a ouvidoria foi ocupada por quatro servidores diferentes, com tempos bem distintos entre eles: 1) Eliana Pinto - entre abril de 2003 até janeiro de 2011; 2) José Eduardo Romão - março de 2011 até janeiro de 2015; 3) Luís Henrique Fana - janeiro de 2015 até março de 2016; 4) e Gilberto Waller Junior - março de 2016 até atualmente. A nomeação do OGU se dá por edição de portaria pelo Ministro da Casa Civil (Decreto no 4.734/2003). O Ministro da Transparência, Fiscalização e Controladoria Geral da União (CGU) encaminha à Casa Civil a proposta de nome para tal função.
} 
restringindo a sua liberdade de ação e decisão. De forma geral, o que esses dados mostram é uma deficiência da autonomia política por parte da ouvidoria pública.

Passando para a segunda dimensão, a autonomia técnica, em outra pesquisa, (BORGES, 2012) demonstra que apenas 32,8\% das ouvidorias pesquisadas possuem orçamento próprio. Além disso, parcela significativa das que possuem recursos, estes são provenientes da instituição da qual são vinculadas $(68,1 \%)$, sendo que somente $7,8 \%$ das ouvidorias possuem recursos próprios, o que compromete a garantia de meios materiais e de capital humano, inviabilizando a sua atuação ao tirar "espaços" de circulação e independência que o ouvidor poderia ter, e centralizar as suas ações junto ao órgão em que ele está interligado. Além disso, no Projeto coleta OGU de 2014, quando perguntado sobre as principais dificuldades encontradas pelas ouvidorias federais (mais de uma resposta poderia ser dada), 40\% delas apontaram a escassez de recursos financeiros, $41 \%$ responderam estruturas físicas insuficientes e 60\% referem-se à insuficiência do quadro de pessoal (MENEZES, 2017).

Menezes, Lima Neto, e Cardoso (2016), ao analisarem 93 órgãos e entidades nos quais a ouvidoria possui representação formal com base no Sistema de Organização e Inovação Institucional do Governo Federal (Siorg) em junho de 2014, demonstraram que grande parte dos atos normativos não trata dessa dimensão (autonomia técnica)explicitamente, e quando há menções, elas são vagas. Assim, não está expresso claramente nas resoluções, por exemplo, o caráter de urgência de resposta às demandas do ouvidor, com fixação de prazos, ou o próprio estabelecimento de sanções, caso eles não sejam cumpridos, pressupostos esses que podem garantir o acesso do ouvidor a informações e às mais altas esferas de tomada de decisão. Esses dados também remetem para a debilidade da autonomia técnica dessa instância.

Quanto à terceira dimensão, observa-se que a prestação de contas desenvolvida pela ouvidoria pública pode ser tanto interna quanto externa, e possui três públicos-alvo: o cidadão que a acionou, a sociedade, e o Estado. A interna se refere aos funcionários de determinada organização, contribuindo pouco para o controle social. Já a externa, seria a que envolve mais um modelo maximizador desse tipo de controle, que potencializaria mais o princípio da accountability, e envolveria esses três públicos-alvo simultaneamente em diferentes contextos (LIMA Neto, DURÁN, 2016)

De maneira geral, a prestação de contas desempenhada pelas ouvidorias federais se restringe àquela oferecida ao indivíduo manifestante, não possuindo um caráter mais ampliado. Além disso, como observamos neste artigo, a ideia prestação se restringe muito ao espaço sala de ouvidorias, onde é possível visualizar o tipo de manifestação mais recebida (denúncia, elogio, reclamação, solicitação ou 
sugestão) durante determinado período, tempo médio de atendimento, o perfil do cidadão-manifestante, e filtrar pelos órgãos, entidades e assuntos, dentre outros, que compõem o sistema e-Ouv. Cabe destacar que essas informações não estão previamente em formato de dados abertos, o que inviabiliza fazer comparações mais sistemáticas e ter uma visão mais geral, tendo o leitor que selecionar cada item de interesse por vez; ou então solicitar o acesso aos dados abertos.

Como Menezes (2017) demonstra que apenas 39\% das ouvidorias federais desenvolvem estratégias de comunicação para envolver os cidadãos nas ouvidorias, é necessário desenvolver formas de ação que desempenhem uma justificação pública acerca das ações e envolvimento nas políticas públicas pela ouvidoria, decorrentes das queixas, sugestões e reclamações dos cidadãos, e, assim, reforçar a sua importância institucional e se distanciar de sua imagem que ela seria um canal inerte, apenas para recepção de demandas.

Nesse sentido, cabe destacar a Empresa Brasil de Comunicação(EBC), na qual compete ao ouvidor-geral a produção de, no mínimo, 15 minutos de programação semanal, a ser veiculada pelos canais públicos de comunicação da empresa (Menezes; Lima Neto; CARdoso, 2016); e o programa "Espaço Ouvidoria" veiculado uma vez por mês (última sexta-feira) na Rádio Senado, que exibe os trabalhos da ouvidoria da "Câmara Alta" brasileira (QUINTÃo, 2015). A comunicação oficial se faz importante para a ouvidoria ter mais respaldo e trânsito internamente entre os órgãos públicos e também para desenvolver mais a transparência de suas ações junto ao público externo, o que poderia reforçar a sua importância para o atendimento das demandas dos cidadãos.

Ademais, deve-se preocupar em publicizar nos próprios websites das instituições e órgãos públicos os trabalhos desempenhados pela ouvidoria, como forma de responder aos cidadãos como um todo, sobre sua atuação e atribuição desempenhada, sempre respeitando o sigilo do cidadão que a acionou, uma vez que esse é um pressuposto da autonomia técnica da ouvidoria ${ }^{16}$.

Quintão (2015), ao analisar o fornecimento de informações sobre a ouvidoria nos websites das assembleias estaduais, constatou que as informações são sucintas e referem-se basicamente ao conceito, funções ou objetivos e formas de contato com a ouvidoria ${ }^{17}$. Por exemplo, das 14 assembleias legislativas que possuíam

\footnotetext{
${ }^{16}$ Quintão (2015) demonstra que entre janeiro e julho de 2014 há apenas uma notícia, tanto no site da Câmara dos Deputados quanto do Senado, a respeito da atuação dessas ouvidorias, o que demonstra a baixa publicização dos seus desempenhos. Essa notícia se refere ao fato do ouvidor da Câmara ter conseguido a liberação do FGTS para funcionários terceirizados dessa Casa (mediação de conflitos). Os outros "acontecimentos" se referem a seminários e encontros que pautam sobre esse instituto.

${ }^{17}$ Além da disponibilização de informações, o autor analisa a posição da ouvidoria e o acesso às ouvidorias nesses websites. Para saber mais ver: Quintão (2015)
} 
ouvidoria no momento da pesquisa, apenas cinco assembleias informam quem é o ouvidor (Amazonas, Bahia, Ceará, Minas Gerais e Paraíba), sendo que somente em duas delas há a apresentação de como o processo de escolha do ouvidor é feito (Minas Gerais e Paraíba); três não disponibilizam quaisquer informações sobre a ouvidoria parlamentar, e oferecem somente o campo para preencher a mensagem a Ihes ser enviada: Piauí; Sergipe; e Tocantins; e em nenhuma delas há quaisquer notícias ou relatórios acerca dos trabalhos desempenhados por esse mecanismo.

Outro ponto que merece destaque é acerca do perfil dos manifestantes da ouvidoria. Em relação às ouvidorias públicas federais, ele se caracteriza por serem mais homens, brancos, até 40 anos, da Região Sudeste, em que aparece com maior incidência o Estado de São Paulo, o que demonstraria uma característica de maior centralidade de recursos por parte dos demandantes ${ }^{18}{ }^{19}$. A questão que se coloca é a baixa circulação informacional sobre o papel da ouvidoria e sua forma de atuação, em que o público que a reconheceria como um arranjo de reivindicação de demandas e direitos seria restrito àqueles situados em espaços com melhores status socioeconômicos.

No que tange à participação das ouvidorias em ações compartilhadas com outras ouvidorias, conselhos ou institutos de participação social, há necessidade de avanços- apenas $40 \%$ das ouvidorias federais pesquisadas realizam ações conjuntas e, mesmo assim, prevalece o caráter geográfico e/ou setorial nessas relações de cooperação (MENEZES, 2017). Diante disso, propõem-se a definição de um novo desenho das ouvidorias públicas ainda não formulado pela literatura, com vistas a tornar as ouvidorias com feições mais democráticas e autônomas (LYRA, 2014; CARDOSo, 2012): a garantia de assento do ouvidor nos conselhos de políticas públicas, principalmente junto àqueles que têm vinculação direta com os ministérios ou secretarias de governo.

Esse desenho propiciaria que os discursos presentes na ouvidoria se inserissem nessas instituições participativas (fortalecimento de um sistema participativo), incorporando novas vozes no processo político, com expansão da representação discursiva, com choques e disputas entre eles, o que fundamenta a ideia de accountability discursiva (DRYZEK, 2000). Ocorreria uma maior integração nessas

\footnotetext{
${ }^{18}$ Consulta: sala de ouvidorias - acesso dia 20/2/2017.

${ }^{19}$ Admitindo que os dados sobre o perfil do cidadão-manifestante da ouvidoria ainda são poucos e esparsos, essas evidências vão ao encontro da pesquisa feita por Mario (2011) sobre quatro ouvidorias municipais do Estado de São Paulo (Campinas, Santos, Santo André e Jundiaí). Nessa pesquisa, a autora demonstra que o perfil dos "cidadãos demandantes", de maneira geral, é o de tendência mais "média para elitista", com alta concentração de escolaridade de ensino médio ou superior; e advindos de regiões com índices de menor exclusão social. 0 mesmo acontece com Quintão (2015), que, ao analisar o SIS Ouvidor, nos anos de 2012 e 2013, da Câmara federal brasileira, encontrou um padrão semelhante.
} 
instâncias de participação social, além de aumentar a relação da ouvidoria com a sociedade civil e sua presença no ciclo de políticas públicas, o que incrementaria a sua integração com outras instituições participativas, e aperfeiçoaria o processo de prestação de contas.

\section{Ouvidorias e os ministérios federais: apontamentos exploratórios}

De forma exploratória, buscou-se analisar os atos normativos da ouvidoria dos ministérios federais e como esse canal é retratado nos seus respectivos websites, como uma proxy para entender quais medidas estão sendo desenvolvidas no sentido da ouvidoria "falar" para o público externo, especialmente para as pessoas que nunca a acionaram, com o objetivo de prestar contas sobre a sua "eficácia política". A justificativa de examinar os ministérios se dá por nem todos estarem integrados ao sistema e-Ouv (dez ministérios estão inseridos nesse sistema ${ }^{20}$ ), o que permite comparar e examinar as diferenças presentes na forma de apresentar e integrar as ouvidorias no corpo institucional ${ }^{21}$, além de investigar a sua atuação em um contexto direto com as políticas públicas.

Para ter acesso aos atos normativos e indagar sobre a política de comunicação desenvolvida pela ouvidoria, tais informações foram requeridas via Lei de Acesso à Informação (LAI), pelo sistema e - $\mathrm{SIC}^{22}$, nos meses de novembro e dezembro de 2016, com um texto padrão, e foram enviadas para 19 Ministérios. Este número é decorrente da congruência entre aqueles que estavam presentes nesse sistema com a reforma ministerial realizada pelo Governo Temer. Ou seja, havia desatualização no e - SIC no momento de envio da solicitação. O Quadro a seguir demonstra a relação das ouvidorias ministeriais investigadas (Quadro 02).

\section{Quadro 02 - Relação das ouvidorias ministeriais pesquisadas}

\begin{tabular}{|c|l|}
\hline $\mathbf{N}^{\circ}$ & Ministérios \\
\hline 1 & Agricultura, Pecuária e Abastecimento - MAPA \\
\hline 2 & Ciência, Tecnologia, Inovações e Comunicações - MCTIC \\
\hline 3 & Cultura - MinC \\
\hline 4 & Defesa - MD \\
\hline
\end{tabular}

\footnotetext{
20 São eles: Agricultura, Pecuária e Abastecimento; Ciência, Tecnologia, Inovações e Comunicações; Defesa; Educação; Pesca e Aquicultura; Previdência Social; Cidades; Minas e Energia; Desenvolvimento, Indústria e Comércio Exterior; Esporte; e Turismo.

${ }^{21}$ De acordo com a Portaria no 50.252,de dezembro de 2015, a adesão ao sistema e-Ouv é voluntária e mediante manifestação expressa da autoridade competente do órgão ou entidade.

${ }^{22}$ Sistema eletrônico do serviço de informação ao cidadão.
} 


\begin{tabular}{|c|l|}
\hline 5 & Educação - MEC \\
\hline 6 & Fazenda - MF \\
\hline 7 & Integração Nacional - MI \\
\hline 8 & Justiça - MJ \\
\hline 9 & Meio Ambiente - MMA \\
\hline 10 & Planejamento, Orçamento e Gestão - MP \\
\hline 11 & Previdência Social - MPS \\
\hline 12 & Saúde - MS \\
\hline 13 & Turismo - Mtur \\
\hline 14 & Cidades --MCidades \\
\hline 15 & Desenvolvimento Agrário \\
\hline 16 & Esporte - ME \\
\hline 17 & Minas e Energia - MME \\
\hline 18 & Relações Exteriores - MRE \\
\hline 19 & Transportes, Portos e Aviação Civil - MT \\
\hline
\end{tabular}

Fonte: elaboração própria

Destaca-se que três ministérios não possuem ouvidoria formal em sua estrutura: Transportes, Portos e Aviação Civil; Cidades; e Meio Ambiente. Dos 16 restantes, em todos esses não há uma resolução específica sobre a ouvidoria. Suas atribuições estão expressas no regimento interno criado via portaria, e com datas recentes, situados entre os anos de 2010 a 2016. A primeira ouvidoria criada foi a da Previdência, em 1991, via decreto.

Grande parte das ouvidorias ministeriais está situada no gabinete do ministro, e essas possuem duas assessorias junto a elas; as exceções são: a ouvidoria do Ministério da Fazenda, que se localiza na Secretaria executiva desse órgão; a Ouvidoria consular do Ministério das Relações Exteriores, que é uma unidade da Subsecretaria - Geral das Comunidades Brasileiras no Exterior; e a Ouvidoria do SUS, que integra a Secretaria de Gestão Estratégica e Participativa do Ministério da Saúde. Ressalta-se que a Ouvidoria Geral do SUS foi criada em 2003, por meio de solicitação da 12a Conferência Nacional de Saúde, e busca integrar as ações estratégicas da política de saúde de forma descentralizada nos três entes, e promover consultas públicas por meio de ouvidorias itinerantes para que os cidadãos possam se integrar mais da tomada de decisões (ANTERO, 2014). Por fim, salienta-se que a ouvidoria do Ministério do Planejamento é voltada para o servidor público, ou seja, tem como foco o público interno do poder público federal, sendo assim chamada de Ouvidoria do Servidor.

Ao ouvidor desses ministérios é atribuído cargo de confiança, e ele é escolhido pela equipe do ministro em questão. Ao se analisar os atos normativos dessas 
ouvidorias ministeriais, chama atenção a ouvidoria do Ministério da Cultura. No regimento interno está expressa a preocupação de uma maior integração e auxílio de diversos setores desse ministério para com a ouvidoria, o que simplifica o acesso e o trâmite da ouvidoria dentro da organização, tendo mais subsídios para elaborar pareceres e sugestões de ações. Além disso, há claramente uma preocupação de assegurar autonomia técnica para ela, especialmente ao garantir penalidades e sanções quando requerimentos da ouvidoria não são respondidos pelos órgãos internos no tempo estipulado nesse ato normativo.

Contudo, de forma geral, as competências e funções da ouvidoria estão redigidas de forma muito sucinta nos respectivos regimentos internos, enfatizando o seu papel de disponibilizar informações demandadas pelos cidadãos, e a função de processamento e tratamento das manifestações recebidas pela pasta em questão. A sucintez sobre a ouvidoria nos regimentos internos específicos pode ser justificada pelo fato de tais questões estarem inseridas na instrução normativa da OGU, a qual esses ministérios acompanham.

Sobre a política de comunicação da ouvidoria, tem-se que em alguns casos foi respondido que a comunicação dos relatórios produzidos pela ouvidoria é feita principalmente de forma interna, como aconteceu com o Ministério das Relações Exteriores ao mencionar a Ouvidoria Consular. Tal acepção pode fazer uma aproximação para com o campo teórico da ouvidoria como um instrumento de gestão, com atuação de dentro para dentro, visando à eficiência administrativa e com uma racionalidade mais instrumental, como exposto anteriormente neste artigo. Em outros casos, ocorreram menções sobre os relatórios publicizados nos websites, e, inclusive, eles são facilmente visíveis em seus sítios, como acontece com os Ministérios da Cultura e da Agricultura, Pecuária e Abastecimento. Porém, ocorreram algumas respostas segundo asquais a própria sala de ouvidoria seria um espaço de divulgação de suas ações, e conforme apresentado na seção anterior, isso poderia ser problemático, por ser um painel congelado que não permite visualizar a eficácia política desse instituto, ou seja, a influência política do envolvimento do cidadão perante a ouvidoria.

Nesse sentido, foram examinados os portais de todos os ministérios federais, como forma de uma proxy de importância institucional da ouvidoria, e analisados o seu posicionamento, a facilidade de visualização, e as informações disponibilizadas nos sítios eletrônicos, variáveis essas que podem contribuir ou não para o uso desse mecanismo (RAUPP; PINHO, 2013). 
Quanto ao posicionamento da ouvidoria, de forma geral, ele se divide em dois formatos principais: ou no canto superior ${ }^{23}$; ou na barra de informações na lateral esquerda. O primeiro formato é mais visível, o que facilita a acessibilidade à ouvidoria, enquanto o da parte inferior da homepage faz com que a palavra ouvidoria não seja vista logo de imediato, sendo necessário rolar a página, o que dificulta o seu acesso, o que pode desestimular o cidadão a registrar a sua manifestação (PINHO, 2008). Ressalta-se que nos Ministérios da Educação, Meio Ambiente, e Relações Exteriores não há o ícone ou informação sobre ouvidoria no website. Inclusive foi consultada a barra de busca e o mapa de site e não há quaisquer menções sobre ouvidoria. No Ministério do Planejamento, a Ouvidoria do Servidor se localiza na parte inferior do site, com baixa visualização, dentro da aba "contato". No caso do Ministério da Saúde, a Ouvidoria Geraldo SUS não aparece na barra de busca ou no mapa do site, e só é possível visualizá-la quando descemos a barra de rolagem e aparece a marca do Disque Saúde, com um pequeno escrito: Ouvidoria Geral do SUS.

Sobre as informações disponibilizadas sobre esse canal, percebe-se uma variedade entre os ministérios analisados: a maior parte somente disponibiliza uma breve descrição a respeito da ouvidoria (suas finalidades e competências) e formas de contato, sendo essas de acordo com o padrão do Sistema e-Ouv, em que há os ícones para registrar uma denúncia, reclamação, solicitação, sugestão ou elogio ${ }^{24}$. Outros ministérios procuram oferecer um conteúdo mais atrativo e dinâmico sobre a ouvidoria pública, como o Ministério do Esporte, que oferta vídeos educativos sobre as atribuições da ouvidoria. Todavia, apenas 5(cinco) ministérios disponibilizam os relatórios de atividade na própria seção da ouvidoria: Agricultura; Cultura; Defesa; Fazenda; Justiça; e Trabalho e Previdência Social. Desses, o mais completo é o da Cultura, com maior periodicidade de produção (mensal) e informações mais específicas, que contemplam as manifestações filtradas pelos órgãos que o compõem, característica sociodemográfica dos demandantes, e até mesmo exemplos de recomendações da ouvidoria diante de casos sensíveis e de difícil trato, como disponibilização de informações que requeiram trabalhos de análise e interpretação para os servidores, o que nos aproxima de visualizarmos o trabalho desempenhado desse mecanismo.

\footnotetext{
${ }^{23} \mathrm{O}$ ícone ouvidoria no canto superior acontece nos seguintes ministérios: Agricultura, Pecuária e Abastecimento; Ciência, Tecnologia e Comunicações; Cultura; Defesa; Esporte; Fazenda; Indústria, Comércio Exterior e Serviços; Justiça e Segurança Pública; Transparência, Fiscalização e CGU. Cabe ressaltar que no Ministério da Cultura esse ícone se encontra na barra superior central sem evidência, com fonte pequena e sem destaque para ele.

${ }^{24}$ Interessante destacar que, quando requerido, o ator normativo da ouvidoria do Ministério das Cidades foi informado de que não havia esse mecanismo em sua estrutura formal. Porém, ao analisar o site, também no mesmo período que foi feita a resposta (janeiro de 2017), é possível encontrar o ícone ouvidoria no seu website, porém ele somente reflete o enquadramento do Sistema e-Ouv.
} 
Todavia, como salientado anteriormente, a política de comunicação desenvolvida e até a ideia de prestação de contas é muito limitada, tomando como base uma lógica mais particularista, ou seja, para aquele que acionou a ouvidoria, e não voltada para a coletividade dos cidadãos. Além disso, os próprios relatórios não demonstram qualquer ação demandada pela ouvidoria, ou alguma atribuição desenvolvida por ela por meio da magistratura de persuasão e/ou mediação de conflitos.

Enfim, percebe-se uma baixa publicidade do que é feito a seu respeito nos seus sites institucionais, materializando o que poderia ser classificado como subinformação: "uma informação totalmente insuficiente que empobrece demais a notícia que dá, ou até mesmo uma informação que não informe de fato" (SARTORI, apud PINHO; WINKLER, 2007, p. 2), ou seja, são informações pouco relevantes e decisivas do ponto de vista político.

\section{Considerações finais}

No primeiro momento, foi realizada uma discussão bibliográfica acerca das ouvidorias públicas no Brasil, ressaltando os seus três campos teóricos principais: 1) instrumento de gestão; 2) canal de comunicação; 3) instância participativa. Esses três campos são construídos com base em tipos ideais, o que significa que há confluências e encontros entre eles, não estando isolados entre si. Porém, o que se buscou fazer foi demarcar os paradigmas, princípios e pressupostos predominantes de cada um deles.

Posteriormente, com base em dados secundários e pesquisas publicadas anteriormente, foi feita uma análise dos principais problemas das ouvidorias, principalmente com base em três eixos: autonomia política; autonomia técnica; e prestação de contas. As duas primeiras dimensões estão inseridas dentro de um jogo político mais direto entre o titular da ouvidoria e o órgão ou instituição que ele exerce monitoramento. Já a prestação de contas é mais assegurada pela própria Lei de Acesso à Informação (LAI). O cerne da questão é repensar a política de comunicação a ser adotada, com maior divulgação e justificação pública das sugestões e dos pareceres da ouvidoria para além do público interno. Nesse sentido, a aproximação entre os campos canal de comunicação e instância participativa pode ser frutífera para fomentar a mobilização de públicos e o processo comunicativo, caso esse seja conformado de forma sistêmica.

Nota-se que o discurso presente no sistema de ouvidorias públicas federais, por meio de sua instrução normativa, considera a ouvidoria mais como uma instância participativa, ao assegurar e associar os termos participação e controle de forma próxima, e a colocando de forma semelhante a outras instituições participativas 
como os conselhos e as conferências temáticas. Como mencionado anteriormente, a menor parte das ouvidorias públicas federais realiza ações conjuntas com outras instituições desse tipo. Assim, corre-se o risco de esticar demais o conceito de ouvidoria, (conceptual stretching) (COLLIER; MAHON, 1993; SARTORI, 1970), e colocar muito peso em sua atuação (o dever ser), perdendo densidade e rigor conceitual. Assim, a ouvidoria no presente contexto deve ser vista como um acesso: como um mecanismo de identificação de problemas, que permite o recebimento de preferências, reivindicações, sugestões dos cidadãos, de caráter mais individual, ampliando os espaços que ele possui para apresentar a sua manifestação, com uma relação mais unilateral (do cidadão para o aparato estatal).

Como forma de interligar a ouvidoria com os arranjos de participação institucionalizados, e assim integrar os discursos em distintas arenas, foi proposto um desenho ainda não elaborado pela literatura: a garantia de assento do ouvidor nos conselhos de políticas públicas, principalmente junto àqueles que têm vinculação direta com os ministérios ou secretarias de governo. Esse design acoplaria mais arenas discursivas entre si, além de possibilitar a representação de novas vozes no processo político.

Por fim, novas agendas de pesquisa precisam ser desenvolvidas sobre a ouvidoria pública, inclusive com novas perspectivas metodológicas e desenhos de pesquisa. Grande parte dos estudos consiste na análise de resoluções formais para mensurar o desenho institucional da ouvidoria, e assim a sua forma de atuação, o que pode ser uma estratégia limitada por não compreender as relações de poder em que a ouvidoria se insere, e as instituições informais presentes nesses contextos. Advogamos a necessidade de se fazer estudos de caso e pesquisa comparada, que utilizem técnicas como entrevistas em profundidade e observação participante, para entendermos as motivações para implantar a ouvidoria, a sua forma de adoção, e o seu potencial democratizante; ou então analisar o processo de prestação de contas desenvolvido por meio da análise dos enquadramentos sobre a ouvidoria nos seus respectivos websites e relatórios de atividades.

Nesse sentido, o caso Ministério da Cultura é um exemplo paradigmático. Uma agenda de pesquisa futura seria buscar entender o porquê do seu regimento interno garantir maior autonomia técnica a essa ouvidoria ministerial quando comparada a outras, além de dar visibilidade e facilitar o acesso aos relatórios analíticos do seu trabalho no seu website. Indaga-se se esse fenômeno é decorrente do processo de institucionalização da política cultural, que seria menos insulada burocraticamente e tecnicista, e, assim, tendo um caráter mais plural e ampliado, seria condicionada a ser mais aberta às demandas da sociedade civil e dos movimentos sociais. Entretanto, cabe observar se existem certos padrões de comportamento que 
procuram limitar os trabalhos desse instituto (e como eles operam), o que não pode ser mensurado meramente por meio de resoluções formais, a exemplificar o fenômeno do corporativismo.

Por último, especificamente nos estudiosos que defendem a formulação da lista tríplice por conselho independente para a escolha do ouvidor, faz-se necessário compreender como se dá a dinâmica de decisão, se esta possui um caráter dialógico público ente a sociedade civil envolvida: como se formata a troca argumentativa e de debate nesses fóruns e assembleias; quais entidades civis possuem vozes e participam desse processo, e a justificativa dessas entidades estarem participando desse processo decisionístico e não outras; qual ator é o moderador da discussão; o local onde acontece a deliberação; o tempo de fala de cada participante; o número de representantes de cada organização civil; se o voto é aberto ou não; as possíveis assimetrias de poder existentes nesse processo de tomada de decisão etc. Enfim, todas essas perguntas ficam no ar e sem respostas claras quando se pensa a eleição indireta do ouvidor por meio da sociedade civil. Ainda mais que a decisão final para a elaboração da lista tríplice dá-se por meio do método agregativo da regra da maioria, com os três nomes que receberam mais votos. Por meio de estudos dessa natureza, poderia ficar mais evidente a heterogeneidade de projetos políticos existentes dentro da própria sociedade civil, e do próprio Estado em diferentes contextos políticos, demonstrando que a relação entre o Estado e a sociedade é marcada por multiplicidades de conflitos, de vontade política, e de construções de ideias e projetos de acordo com determinadas situações históricas.

Conclui-se que o principal obstáculo que cerca a ouvidoria pública se refere ao precário desenvolvimento de prestação de contas para com a sociedade como um todo, o que inviabiliza o fomento da própria accountability. Pôde-se observar que as trocas discursivas sobre o objeto de estudo ficam muito restritas ao seu público interno e aqueles que acionaram esse mecanismo, com uma postura, muitas vezes, de formato mais reativo ${ }^{25}$. Além disso, estudos que busquem avaliar e mensurar tal aspecto ainda são muito incipientes; provavelmente por, muitas vezes, envolverem a necessidade de coleta de dados junto a ouvidores e sua equipe por meio de entrevistas, ou então a observação ao longo do tempo da publicização de suas ações nos devidos meios.

\footnotetext{
${ }^{25}$ Silva et al. (2012), em um survey com 300 casos em Belo Horizonte e interior de Minas Gerais, demonstram que $53 \%$ não sabiam como levar suas reclamações ao governo. Desses, $32 \%$ nunca ouviram falar em ouvidoria, e $47,7 \%$ afirmaram que ouviram só um pouco. Por outro lado, 81,7\% possuem interesse em levar suas reclamações ao governo, mas $94,7 \%$ nunca procuraram a ouvidoria. Os referidos dados demonstram o nível incipiente de conhecimento sobre a ouvidoria pública, e até a necessidade de uma política de comunicação mais robusta sobre esse instituto.
} 
Apesar de reconhecer que avanços foram feitos a respeito da ouvidoria pública, especialmente das federais, decorrentes, principalmente, da implantação da LAI e do Sistema e-Ouv, que ampliaram as manifestações dos cidadãos junto a esse mecanismo, defendemos que três fatores principais se inserem nesse processo para a sua otimização: autonomia pública (política e técnica); cooperação entre os órgãos governamentais envolvidos para que a sua recomendação tenha maior impacto; e sua capacidade de atuação e de comunicação, principalmente junto à sociedade civil.

\section{Referências Bibliográficas}

ANTERO, SamuelA.Evaluating the participatory potential of the Brazilian Active Model in the Federal Executive Branch: an implementation perspective. Research Proposal. PHD in Government: University of Canberra, 2014.

ANTUNES, ChussyK. S. A ouvidoria em sua bi função: uma ferramenta de inteligência competitiva à gestão. Revista Gestão Pública. Práticas e Desafios, Recife, v. 1, n. 1, p. 144-180, fevereiro, 2010.

BAESSO, Robson de S. Ouvidorias: mecanismos singulares de governança. Anais do XXVII Encontro da Anpad. Rio de Janeiro, 2013.

BAstos, Ana R.; MARChIORI,Marlene.; Moraes MAYA, M DE. Ouvidoria como Processo de Construção de Conhecimento. In: IASBECK, LUIZ C. A (org.).Ouvidoria: mídia organizacional. Porto Alegre:Editora Sulina,p. 78-94,2012.

BoRgES, Doriam (Org.).Sumário Executivo: Pesquisa Diagnóstico das Ouvidorias do Poder Executivo Federal.In: Controladoria Geral da União, Brasília, 2012.

CARDoso, Antônio S. R. Ouvidoria Pública como instrumento de mudança. Textos para Discussão. Ipea, no 1480, Brasília, 2010.

CARDoso, Antônio S. R. Ouvidoria Pública e democracia. In: CARDoso, Antônio S. R; LYRA Rubens P (Orgs.). Modalidades de Ouvidoria Pública no Brasil:terceira coletânea. João Pessoa: Editora Universitária da UFPB, p. 83-102, 2012.

CARdoso, Antônio S. R; Neto, Fernando C. L.; Alcantara, Elton. L. da C. Ouvidoria Pública e Governança Democrática. Boletim de Análise Político-Institucional, no 3. Ipea, p. 51-60, 2013.

COELHO, Silvia R. dosS. Representatividade e representações em ouvidorias públicas. In: IASBECK, LUIZ C. A (Org.). Ouvidoria: mídia organizacional. Porto Alegre: Editora Sulina, p. 95-112, 2012.

COLlIER, David; MAHON, JAMES J. Conceptual "stretching" revisited: adapting categories in comparative analysis. The American Political Science Review, v.87, n. 4, p. 845-855, 1993.

Comparato, Bruno K. As ouvidorias públicas como instrumento de democracia participativa: o exemplo das ouvidorias da polícia. In: 8o Encontro Associação Brasileira de Ciência Política (ABCP), Gramado, 2012.

COMPARATO, BRUNO K. Ouvidorias públicas como instrumentos para fortalecimento da democracia participativa e para a valorização da cidadania. In: MENEZES, Ronald 
A. do; Cardoso, Antônio S. R (Orgs). Ouvidoria Pública Brasileira: reflexões, avanços e desafios. Brasília: Ipea, p. 43-53, 2016.

Constela, Carlos R.; LYRA, Rubens P. (Orgs.). Defensorías del Pueblo y Olvidarías en Iberoamérica: nuevos conceptos y perspectivas. João Pessoa Editora Universitária da UFPB, 2012.

DAGNINO, EVELINA. Construção democrática, neoliberalismo e participação. Revista Política e Sociedade, n. 05, p. 139-164, 2004.

DRYZEK, John. S. Deliberative democracy and beyond: liberals, critics, contestations. New York: Oxford University Press, 2000.

FUNG, Archon.Recipes for public spheres: eight institutional design choices and their consequences.The Journal of Political Philosophy, v. 11, n. 3, p. 338-367, 2003. FUNG, Archon. Varieties of participation in complex governance. Public Administration Review. Special Issue, December, p. 66-75, 2006.

Gomes, Manoel E. A. C. Dos mecanismos de controle à equidade social. Anais do II Seminário de Ouvidores e ouvidorias. Instituto Pró Cidadania, 2006.

GoMes, Manoel E. A. C. Modelos de ouvidorias públicas no Brasil. In: Menezes, Ronald. A. do; CARdoso, Antônio S. R (Orgs.). Ouvidoria Pública Brasileira: reflexões, avanços e desafios. Brasília: Ipea, p. 13-41, 2016.

IASBECK, Luiz C. A. Ouvidoria é comunicação. Organicom: Revista Brasileira de Comunicação Organizacional e Relações Públicas, v. 7, n. 12, p. 14-24, 2010.

IASBECK, Luiz C. A. Competências comunicacionais em ouvidoria. In: IASBECK, LUIZ C. A. (ORG.). Ouvidoria: mídia organizacional. Porto Alegre: Editora Sulina, p. 21-56, 2012.

IzUNZA, Ernesto V.; HeVIA, Felipe de la J. Relaciones sociedad civil -Estado en México: un ensayo de interpretación. Xalapa: Ciesas - Cuadernos para la democratización, n. 4, 2006.

Lavalle, Ádrian G; Vera, Ernesto I. Precisiones conceptuales para el debate contemporáneo sobre la innovación democrática: participación, controles sociales y representación. In:VERA, ERNESTO I.; LAVALLE, Ádrian G. (ORGS.).La innovación democrática en América Latina: Tramas y nudos de la representación, la participación y el control social. México: Centro de Estudios Superiores en Antropología Social, p. 19-80, 2010.

LYRA, Rubens P. (Org.). Autônomas $x$ obedientes: a ouvidoria pública em debate. João Pessoa: Editora UFPB, 2004.

LYRA, Rubens P. Ouvidor: o defensor dos direitos humanos na administração pública brasileira. In: LYRA, RUBENS. P. (ORG.). Participação, democracia e segurança pública a experiência brasileira. João Pessoa: Editora UFPB, p. 65-96, 2008.

LYRA, Rubens P. A ouvidoria no contexto da democracia participativa. Seminário Temático. Anais do 35을 Encontro Anual da Associação Nacional de Pós-Graduação em Ciências Sociais (Anpocs), 2011a.

LYRA, Rubens P. A ouvidoria pública brasileira e a questão da autonomia. Revista Prim@ Facie, v. 15, p. 9-23, 2011b. 
LYRA, Rubens P. Ouvidorias públicas e privadas: farinhas do mesmo saco? In: LYRA, Rubens P. (Org.) Do Tribunal da Plebe ao Ouvidor Público: estudos sobre os defensores da cidadania. Editora da UFPB: João Pessoa, p. 173-193, 2011c.

LYRA, Rubens P. A ouvidoria pública no Brasil: modelos em disputa. Anais do IX Encontro da Associação Brasileira de Ciência Política (ANCP), Brasília, 2014.

LYRA, Rubens P.; LEMOS, Paulo (2014). Propostas Parlamentares e do Governo Federal para um sistema nacional de ouvidorias. In: LYRA, Rubens P. (Org.).A Ouvidoria Pública no Brasil: modelos em disputa. João Pessoa. Editora Universitária da UFPB, p. 15-41, 2014.

MARIO, Camila G. de (ORG.). Ouvidorias públicas em debate: possibilidades e desafios. Jundiaí: Editora Paco Editoral, 2011.

Menezes, Ronald A. do. Ouvidorias públicas federais: análise dos elementos que contribuem para a promoção da gestão social.Textos para Discussão: Brasília: Ipea,2015.

MENEZES, Ronald A. do. Projeto Coleta OGU 2014: um retrato das ouvidorias federais brasileiras. In: Menezes, Ronald A. do; CARDoso, Antônio S. R (Orgs). Ouvidoria Pública Brasileira: reflexões, avanços e desafios. Brasília: Ipea, p. 215-227, 2016.

MENEZES, Ronald A. do. A atuação das ouvidorias públicas federais como instâncias de controle e participação social no Brasil. Textos para Discussão, Brasília: Ipea, 2017.

Menezes, Ronald A. do; Lima Neto, Fernando C.; Cardoso, Antônio S. R. As ouvidorias e o uso público da razão: proposta de um modelo ideal possível à luz dos atos normativos das ouvidorias públicas federais no Brasil. In: MENEZES, Ronald A. do; CARDoso, Antônio S. R (ORGS). Ouvidoria Pública Brasileira: reflexões, avanços e desafios. Brasília: Ipea, p.79-101, 2016.

NASSIF, Gustavo C. As ouvidorias públicas no contexto de um novo modelo de governança. Revista do Tribunal de Contas do Estado de Minas Gerais, v. 73, n. 4, p. 45-60,2009.

OliveIRA, João E. de. Ouvidoria brasileira, estímulo à cidadania - Entrevista para IASBECK, Luiz C. A. Organicom: Revista Brasileira de Comunicação Organizacional e Relações Públicas, v. 7, n. 12, , p. 166-177, 2010.

Pateman, Carole. Participação e teoria democrática. Rio de Janeiro: Ed. Paz e Terra. 1992.

PATEMAn, Carole.Participatory democracy revisited. Perspectives on Politics: APSA Presidential Address, p. 7-19, 2012.

PINHo, José A. G de. Investigando portais de governo eletrônico dos estados do Brasil: muita tecnologia, pouca democracia. Revista de Administração Pública, Rio de Janeiro, v. 42, n. 03, p. 471-493, 2008.

Pinho, José A. G. DE; WINKLER, Ingrid.Dabliu, Dabliu, Dabliu: sociedade da informação. Que informação? Anais do XXXI Encontro da Anpad, Rio de Janeiro. 2007.

QuintÃo, Thales T; CAStRo, Paula P. de. O desenho institucional das Ouvidorias 
Públicas: um debate sobre a efetividade das ouvidorias das Assembleias Legislativas como um canal de comunicação. Anais do V Congreso Uruguayo de Ciencia Política. Associación Uruguaya de Ciencia Política (Aucip), 2014.

QUINTÃo, Thales T. Fala que eu te escuto? O potencial democrático das ouvidorias parlamentares: o caso de Minas Gerais.2015 201f. Dissertação (Mestrado em Ciência Política) - Faculdade de Filosofia e Ciências Humanas, Universidade Federal de Minas Gerais (UFMG), Belo Horizonte.

RAuPP, Fabiano M.; PINHo, José A. G. de. Accountability em câmaras municipais: uma investigação em portais eletrônicos. Revista Administração. São Paulo, v. 48, n. 04, p. 770-782, 2013.

RoMÃo, José E. E. A efetividade da Ouvidoria Geral da União. In: MENEZES, Ronald A. do; CARDoso, Antônio S. R (Orgs). Ouvidoria Pública Brasileira: reflexões, avanços e desafios. Brasília: Ipea, p. 187-201,2016.

Romero, Henrique H.; SANT'ANNA, Francisco C. C. M. O papel das ouvidorias na comunicação pública do Poder Judiciário. Revista do Serviço Público do Brasil, v. 05, n. 02, p. 185-198, 2014.

SANTOS, Boaventurade S.; AVRITZER, Leonardo. Introdução: para ampliar o cânone democrático. In: SANTOS, Boaventurade S. (Org.). Democratizar a democracia: os caminhos da democracia participativa. Rio de Janeiro: Civilização Brasileira, p. 3982,2002 .

SARTORI, Giovanni. Concept misformation in comparative politics. The American Political Science Review, v. 64, n. 4, p. 1033-1053, 1970.

SCHEDLER, Andreas. Conceptualizing Accountability. In: SCHEDLER, Andreas; DIAMOND, Larry; PLATTNER, Marc (Orgs.). The self-restraining State: power and accountability in new democracies. Boulder: Lynne Rienner, p. 13-28, 1999.

Silva, Adriana. C. et al. Por um sistema nacional de ouvidorias públicas. Série Pensando o Direito, v. 42. Ministério da Justiça, Brasília, 2012.

VALDÉS, Daisyde A.Ministério Público, ouvidorias e cidadania: governança e participação. In: LYRA, Rubens P. (Org.). Do Tribuno da Plebe ao Ouvidor Público: estudos sobre os defensores da cidadania. João Pessoa. Editora Universitária da UFPB, p. 271-286, 2011.

Vera, ERnesto I.; LAVAlle, Adrian G. Arquitetura da participação e controles democráticos no Brasil e no México. Novos Estudos, n. 92, p.105-121, 2012.

ZAVERUCHA, Jorge. O papel da ouvidoria de polícia. Revista Sociologias, Porto Alegre, ano 10, n.20, p. 224-235, jun./dez., 2008.

\section{Thales Torres Quintão}

Doutorando em Ciência Política pela UFMG. Contato: thalestq@hotmail.com. 
